MATEC Web of Conferences 44, 01076 (2016)

DOI: $10.1051 /$ matecconf/20164401076

(c) Owned by the authors, published by EDP Sciences, 2016

\title{
Study on Teaching Reformation of Contemporary Art Teaching to University Students on Corel Painter Software
}

\author{
Mei Ni Xiong, Bao Quan Pan ${ }^{a}$ \\ College of Fine Arts, Beihua University, Jilin City, China
}

\begin{abstract}
Contemporary art education started late in China on the basis of western teaching theories formed its own unique system, which has a great influence on Corel Painter software. This paper explores that contemporary art education is analyzed advantages and disadvantages of the influence on the development of Chinese painting, and the solutions are found out to the existing problems, summed up the reality enlightenment of that the contemporary art on the impact of education on Chinese painting development.
\end{abstract}

\section{General instruction}

On the contemporary art education teaching materials, mainly from the West, the system is only a product of modern times. Since the early 1950s, the introduction of "Soviet model", the "sketch teaching system" long-term dominant position, which makes the development of Chinese painting to a certain extent, too much emphasis on the infected 'Western realism based "colours. Eighties and nineties change the status quo of contemporary art education and teaching methods make "student-cantered" has become the consensus of the majority of school education. And in the final analysis, the development of Chinese painting and contemporary art education on how mutual integration, how to seek common ground, how to learn from each other, the development of both what constraints they are facing a series of problems have become more apparent, prompting the inheritance and development of Chinese painting has become the most contemporary art education one of the important issues.

On the subject of correlation, the author of the information is available and rare. Correlation of the current works are mostly to be an analysis of the development of Chinese painting from the perspective of traditional art education, lack of breath new era. Influence of contemporary art education for the development of Chinese painting is to better summarize now able to meet the needs of the development of socialism with Chinese characteristics, and promote national love of national culture and develop.

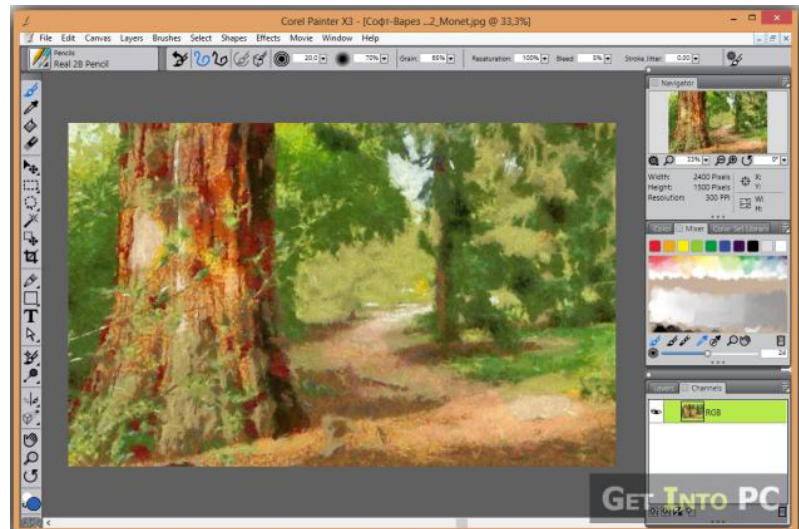

Figure 1. Corel painter X3 download free version for windows and mac

\section{The basic idea of contemporary art education}

With the changing times, contemporary art education has been given a new era of more spirit and values in heritage and inheritance will appear in many of the vitality and new understanding. Ming Dong Qichang in the "painting Chanshi Essay," also said: "The painter Kamijina pole for the case, another to add to Kamijina Yiping over who said natural then for God." Zhuangzi also think simple and natural as the highest realm. He proposed "both carved both clumsy, reverted to the Park," "simple and indisputable beauty of the world Mo 'point of view. That is, he is not opposed to artificial artistic process, but the goal is still to reach the return process simple and natural realm, which is the high degree of unity between man and nature realm, namely "World and I, and students, all things with me as a" to enter into the realm of Heaven. Huang landscape painting throughout profound works,

\footnotetext{
${ }^{\mathrm{a}}$ Corresponding author: baoquanpan@126.com
}

This is an Open Access article distributed under the terms of the Creative Commons Attribution License 4.0, which permits unrestricted use distribution, and reproduction in any medium, provided the original work is properly cited. 
Shi Qi pen ink out of the poor, and each time he gave the next dye dyed leaving gaps.

The entire screen layout, tend to put the picture of a mountain, although black ink round, but it does not make people feel choking. The actual situation in which the secret lies is in the handling of the screen, revealing a little bit of virtual white. Only the saints, "Road", "reason" with their spirit of harmony, trigger the unlimited mental state. The ancients also realized in the form of landscape view of the "Road" and on the "truth" of deep understanding. Landscape scenery of the gas is to borrow the influence of the mind can be detached in order to enter the realm of Takashi more elegant.

Overall, the four basic schools of Chinese classical aesthetics point of view, although somewhat different, but there is a very obvious thing in common. That are advocating Heaven, things I harmony, harmonious people I do not emphasize the antagonistic relationship between man and nature. The formation of this ideology is affected by the ideology of ancient society. From primitive society to rely on the natural slave class division, agriculture and light industry and then re-feudal society, the traditional subsistence peasant economy of production, backward social system so that people have a natural nature admiration, any resistance to natural disasters mean humans, and therefore the relationship between man and nature was the ancient Chinese spontaneously as one unified relationship; and now, with the progress of society, the advent of the industrial age machines, productivity is greatly improved, production expanded rapidly diminishing reliance on nature. The social economical and extremely underdeveloped, people of the world, has been deeply Confucian aesthetic values, the impact of the Taoist aesthetics, aesthetics of Chug, Buddhist aesthetics thought.

In summary, the Confucian aesthetic beauty in the pursuit of unity, they pursue personal beauty, and ultimately for life and art; Taoist pursuit of truth and beauty of unity. Their pursuit of natural beauty is the ultimate realization of art and life. Chu Sao aesthetic and moral is unity throughout the pursuit, the pursuit of beauty and Zen Buddhist aesthetic unity. When aesthetic ideology of Confucianism, Taoism, Chu, Buddha, although there are many differences in their philosophy and awareness, but they are exploring the aesthetic image of Chinese painting, but also the similarities together to form ideas from contemporary art education to a very important role. So that in the contemporary art education background, shaping the personality characteristics of different artists. We should admit that Chinese painting is the beginning of self-reliance in the Western impact and modernization. Contemporary art education is neither a Westernized, nor is along the natural development of the traditional track, but the Chinese people with advanced culture as the reference, the development of individual creative thinking, discover and create their own value. In order to play as the main driving force of subjective creativity, school education for learning pathways, inheriting Chinese traditional education on the basis of ideology, from Western educational model, starting from China's basic national conditions, to develop a number of professional painting, oil painting, printmaking, design, sculpture, etc. for the community to cultivate outstanding talents specialized art education, improve with distinct Chinese characteristics art education system.

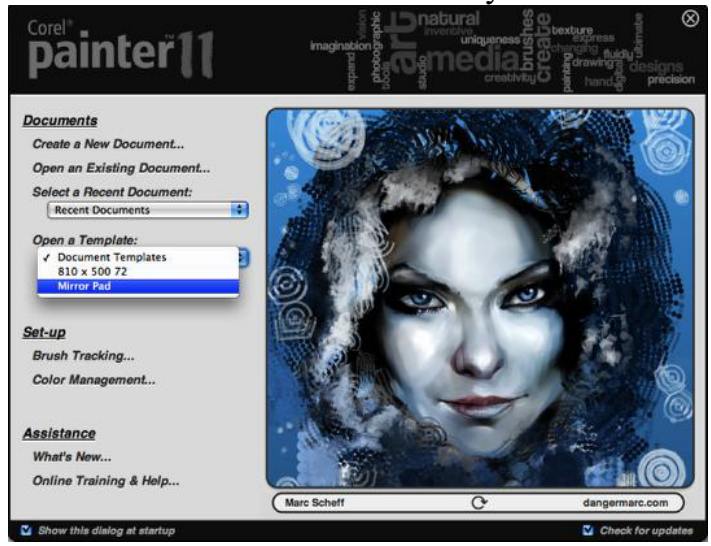

Figure 2. People face renderings

\section{Chinese painting as a symbol of Chinese art}

Chinese painting as a symbol of Chinese art, has developed a number of years, has experienced a long history. Its development and development of traditional art education is basically synchronized. Traditional art education model for studying the development of selfcontained Chinese painting provides a strong guarantee, but the crisis has brought to the development of Chinese painting, Chinese painting may lead to the development of stagnation and rigid.

With the introduction of Western culture, contemporary art education has been given a new content and features, traditional art education has been seriously challenged, and Chinese painting is no exception. Chinese and Western cultures fierce collision, given the contemporary art education conform to the trend of the times, and the Chinese have a tendency to weaken the function of painting, we can see the impact on Chinese painting contemporary art education development is enormous. Therefore, Chinese painting to have sustainable development, we must look for a path.

Given the cultural heritage and cultural traditions there are significant differences among different ethnic, fusion of contemporary Chinese painting art education and the presence of significant challenges, mainly as follows: Western contemporary art education curriculum is based on the theory, although trying to achieve Western reconcile, western system in order to mark the traditional Chinese painting art education is based on the poetry of learning-based, it is trying to achieve a comprehensive innovation in the original basis. Since the starting point of contemporary art education and traditional art education, the focus is different. Should contrary to objective laws, not according to the actual situation of contemporary art education and the development of Chinese painting, blindly impose two very different systems together, will generate a lot of negative impact, but we should make an objective assessment, can not ignore the contemporary the positive role of art education for the development of Chinese painting. 
Contradictions are opposites, we study the impact of Chinese contemporary art education in the process of painting effects, specifically requires an objective analysis of contemporary Chinese painting art education teaching, writing produced. This article from the aspect of two dimensions, the use of comparative approach, in teaching, through the teaching objectives, teaching methods, teaching materials, teaching content, teaching evaluation analysis of differences in traditional and contemporary art education art education; in the creative aspects of, will be an inspiration on Chinese painting, technique, emotion comparative study, summed up the pros and cons of contemporary art education for the development of Chinese painting, but overall, pros and cons, more harm than good.

Because of our long-term in a feudal society, and the ancient social, political, cultural and systems are designed to meet the needs of the ruling class. The prevalence of the traditional hierarchy is art education, just to satisfy the interests of the ruling class and the service. In this case, the role of art education is major with a strong "into enlightenment, helping Fallon," the. In this historical context, the traditional art education does not have a complete and standardized education system. In particular the teaching process, the main idea is to master personal education based, then painting learners main objective things through observation and copying works of the classical way to achieve the purpose of drawing creation. Contemporary Art education is committed to the community to cultivate creative talents, and the fine arts education in the country gaining in popularity, becoming a national art education. Up to now, we have been gradually achieving the transformation of quality education by exam-oriented education to the "moral, intellectual, physical, aesthetic, labour" comprehensive development.

Visible, education has become the most basic rights of every person, and not a few aristocratic privileges, which will benefit the construction of a socialist harmonious society. Contemporary art education teaching objectives conducive to the development of our comprehensive quality education, improve the overall level of China's national art knowledge. For the construction of a beautiful home that has everything to gain but no harm. However, we also see the shortcomings can not be ignored him an objective reality. Universality corresponds to the peculiarities of contemporary art education is universal knowledge for all students in the art of Chinese painting teaching goal setting, and not as a traditional art education that, according to each student's specific conditions, can amount tailor the most appropriate teaching painting learning objectives and teaching goals at any time to adjust according to the needs of learning. Contemporary Art by differences in education and Chinese painting teaching objectives analysis, summed up contemporary art education exists on the pros and cons of teaching objectives. We can see that they are closely related, the latter is dependent on the former, while drawing on Western art education.

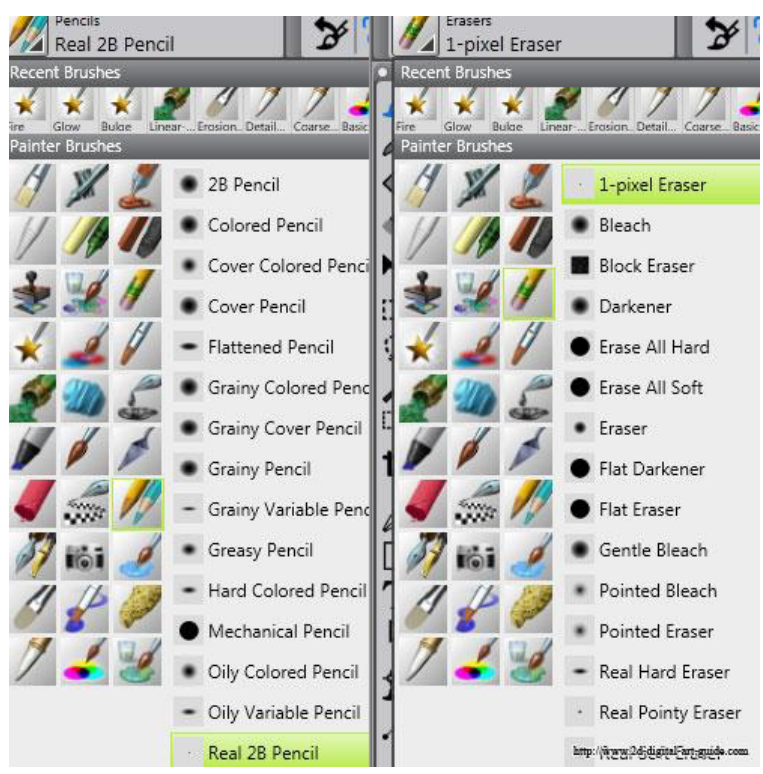

Figure 3. Different pen selection panel

\section{Perfect entrance painting system}

Perfect entrance painting system is established by the test subjects mainly market-oriented to meet the spiritual needs of the national culture as a starting point, the establishment of mechanisms to match the talent of our modern society.

First, adjust the fine arts enrolments appraisal system. We must correct the student selected the correct professional life and values. Put an end to the culture results due to lower admission line, and were blindly irrational choice. Second, the development of relevant is personnel green channel mechanism. For talented people, low scores may be due to cultural studies, and lose the opportunity to further studies. To avoid loss of talent, we can be relaxed too rigid mandatory. Third, to ensure the standard of Fine Arts entrance painting is marking a serious scientific unity.

First, compulsory and elective hours arrangements should be reasonable clear relationship between primary and secondary. Ensure the completion of required courses on the basis of content, complemented by select electives to enrich students' extracurricular knowledge. Secondly, reducing college English, computer, Marxism philosophy and curriculum is such as Introduction to Mao in proportion. In high school, students have to spend a lot of time to learn common subjects of Chinese painting has been selected for professional students, definitely should concentrate on drawing learning Chinese painting. Again, increase appreciation for literature class curriculum arrangements. Development of Chinese painting is based on a comprehensive knowledge of Chinese classical literature, history, philosophy, calligraphy, and other cultural compile engraved based bedding. To truly comprehend the essence of Chinese paintings, we must fully understand its surrounding culture.

How to adjust the structure of teachers, the paper be summarized in the following three aspects. First, the 
rational use of contemporary art education resources. Outstanding art teachers, most choose to stay at the front line state, second-tier cities, thus resulting in a remote area art teacher resource deprivation. For the economically backward areas, should improve conditions for running schools, art teachers to improve the treatment, add some additional financial subsidies to attract relevant professional talent. Second, to improve the art teacher is professionalism of teachers including the character, professional two aspects. Confucian school representative spring and Autumn Period Confucius said: "The body is not to make the trip, its body is not correct, although that is not from." A way to explain is the importance of teachers to teach by example to explain in words. Learn all the prerequisite knowledge is a noble culture of ideological and moral qualities. The so-called style is the man, drawing as it were true. In contemporary art education system, the state in the form of laws requiring teachers to implement lifelong learning system. Through a lot of reading articles, appreciate the works, schools, and other ways to organize collectively to promote teachers' knowledge and constantly updated.

Aesthetic pursuit of Chinese painting is one of the nation's most ethnic characteristics of performance. It leads people to enjoy the beauty; they also placed a love for life is infinite. Song period Sushi once said: "On the painting to the shape, see neighbours' and children", this sentence sharply revealed the aesthetic characteristics of traditional Chinese painting. Depicted object is to pursue the objective nature quite similar, but the shape is quite similar to do the groundwork for the performance of foreshadowing. Process is an evolving aesthetic pursuit of development,, development of Chinese painting is supposed to reflect the people's living conditions in different periods and aesthetics. Look, unlike Song Tang painting paintings, but also different from the Song, Ming and Qing, a generation a generation of style, this style different times, although by the time the political, economic constraints, but for contemporary art education Chinese painting still play an important role can not be ignored.

However, the twenty-first century we modern people really understand our own aesthetic pursuit of it? For the current Chinese painting aesthetic criteria to evaluate the messy nature, which requires us to use the development of a comprehensive, materialist view links to see the world. Always respect the objective laws of development of things, the use of advanced thinking with the times to analyze the problems encountered. Mr. Shi Taolao borrows the words: "When the ink with the times", shows that aesthetic pursuit of Chinese painting should change with the times and constantly evolving.

\section{Conclusions}

Impact of contemporary art education in the 21 st century the development of Chinese painting is multifaceted, deep-seated. This influence is reflected not only in terms of teaching methods of Chinese painting, but also in the creative aspects of Chinese painting. Art Education bears important historical role in the inheritance and development of Chinese traditional culture in. Diverse artistic language is an inevitable trend in the context of traditional Chinese painting new era of development. Theoretical basis of traditional and contemporary art education art education is completely different. Contemporary art education is not only developed on the ideological basis of Confucian philosophy of Chinese classical aesthetics, Taoist aesthetics of Chu on aesthetics and Zen aesthetics, but also by the Western aesthetic thought impressionism, realism, romanticism, neoimpressionist, post-impact of Impressionism and other aesthetic thoughts.

Because of the theoretical basis is different, leading to the existence of a series of discord between the contemporary Chinese painting and art education with a strong ethnic colour issues. Inheritance and development of Chinese painting in the contemporary art education system is facing serious challenges. Where the way contemporary Chinese painting art education development is is an issue that we need to seriously consider. Teaching and writing are two aspects of my departure from traditional Chinese painting made in-depth analysis, pointed out that the healthy development of Chinese painting need to focus on pioneering form of language, aesthetic intention of innovation, creativity and subjective thinking of abandoning traditional culture.

Acknowledgements: Jilin Province Department of Education Projects [2012-344]

\section{References}

1. ZHANG Yao-guang. Lilley. Chinese modern art education in the "Western painting" Complex. Grand Art. 09(2011)

2. Lee slip down modern art education model and the concept of cultural and ecological harmony - of Our universities Normal Art Education in the 21st Century. "Inner Mongolia Normal University (Educational Science Edition). 11(2006)

3. Reflections by Lisa Shuai. Contemporary art trends in China. "Industry and Technology Forum." 2012.

4. Zhang Bing. Explore the aesthetic perspective of Art Education. China-school education, 15(2010)

5. Li Si Hui. On Myth and Art Education of College Students Comprehensive. Heilongjiang Science and Technology Information. 25(2008)

6. Liangtai Sheng. Reform of university teaching of Chinese painting Rethinking. Zong Tai'an College of Education Science, 45(2003)

7. Han Jing. Confront contemporary art education principal institutions of higher art China Forum on -2010. Art Watch, 78(2010)

8. Zhang Jun to stay. On Chinese painting teaching traditional culture. Arts education research, 47(2011) 